\title{
Hybrid laparoscopic colectomy with transluminal colonoscopic specimen extraction - a step toward natural orifice surgery
}

Minimally invasive surgery is the method of choice when colon polyps cannot be removed endoscopically. However, laparoscopic colon resections require a $5-6-\mathrm{cm}$ minilaparotomy to retrieve the specimen. This laparotomy can cause pain, wound infection, and hernia formation [1,2]. We describe a new technique to avoid a minilaparotomy by using a flexible colonoscope for transluminal specimen extraction.

A 70-year-old woman with a polyp in the mid-transverse colon was laparoscopically operated with four trocars $(2 \times 5 \mathrm{~mm}$, $2 \times 5-12 \mathrm{~mm}$ ). Preoperative workup was standard, including bowel preparation. Briefly, laparoscopic dissection consisted of colon mobilization of the hepatic and splenic flexures. The mesentery of the transverse colon was transsected by a 5 $\mathrm{mm}$ Ligasure device (Valleylab, Boulder, Colorado, USA) respecting oncologic principles. Linear Endo-GIAs $(6 \mathrm{~cm}$, blue cartridge, Tyco Healthcare, Norwalk, Connecticut, USA) were used to cut the bowel along the defined proximal and distal resection lines to obtain the specimen. A flexible colonoscope was guided to the end of the distal colon. The colon was opened and the specimen grasped with a wire loop ( Fig. 1).

The specimen together with the colonoscope was then carefully pulled through the distal colon and the anus. The colon was again closed with an Endo-GIA. The resulting tiny colon remnant was removed through one $12-\mathrm{mm}$ trocar. A stapled side-to-side colon anastomosis was carried out and port sites were sutured intracutaneously. Postoperative pain was solely managed by paracetamol. After an uneventful postoperative course the patient was discharged 5 days after the operation.

Natural orifice (transvaginal/transanal) specimen extraction has been described [3-5] to avoid laparotomy for laparoscopic colectomy, but these techniques are limited to female patients or to lesions of the recto-sigmoid colon. Our hybrid ap-
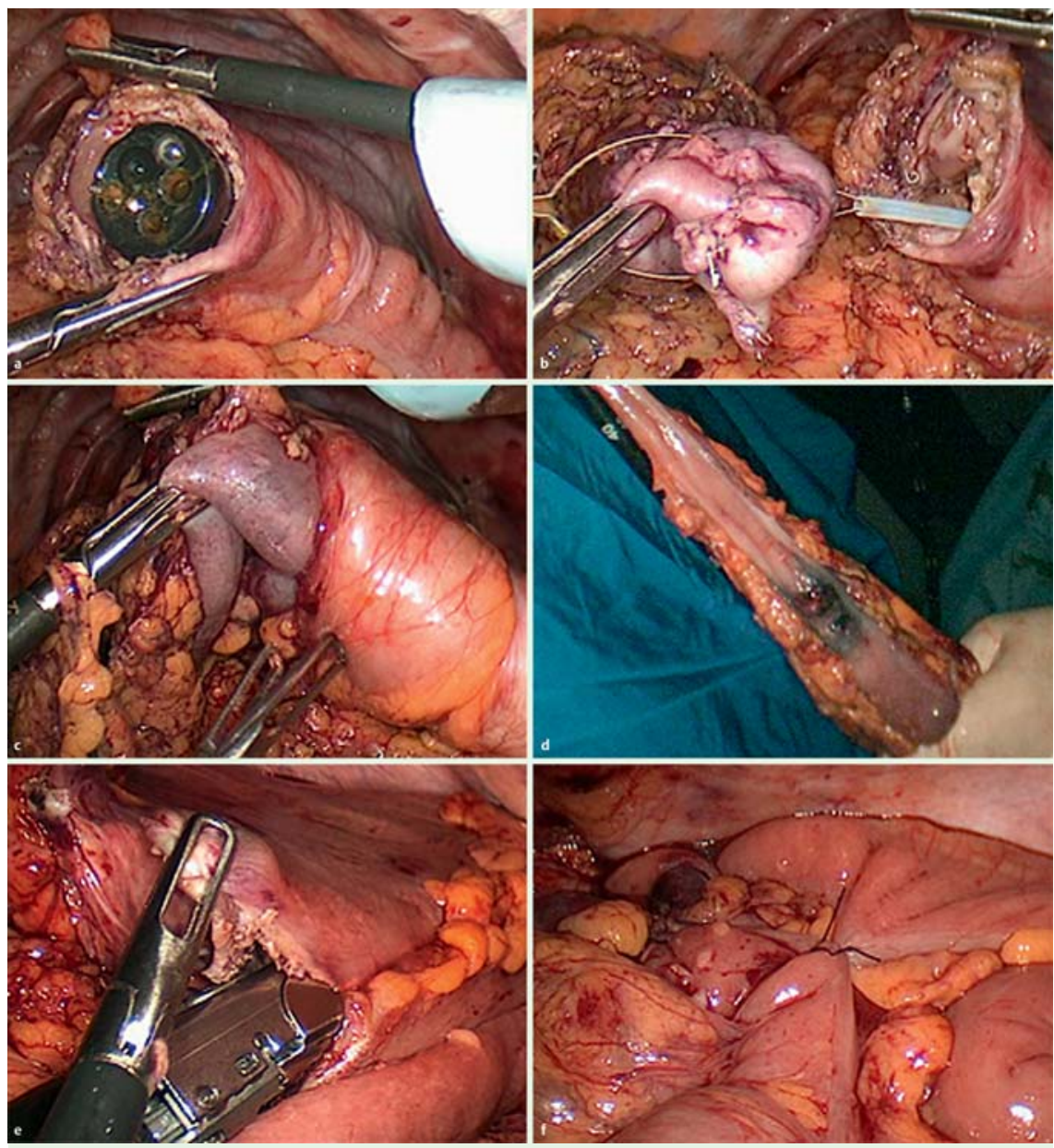

Fig. 1 a The tip of the colonoscope at the previously opened end of the distal colon. $\mathbf{b}$ Catching the colon specimen with a loop wire inserted through the channel of the colonoscope. $\mathbf{c}$ Pulling the specimen through the distal colon together with the colonoscope. $\mathbf{d}$ The anus-retrieved specimen with the preoperatively ink-marked colon polyp. e Creation of the intracorporeal side-to-side colon anastomosis with the help of the Endo-GIA introduced through a small opening in each large bowel site. $f$ Completed colon anastomosis after laparoscopic suturing of the bowel opening required by use of the Endo-GIA.

ly laparoscopic colectomies without laparotomy in order to reduce incision-related morbidity.

\section{Competing interests: None}

Endoscopy_UCTN_Code_TTT_1AQ_2AJ

Endoscopy_UCTN_Code_TTT_1AT_2AZ

\section{S. Saad, D. Schmischke, C. Martin,} T. Schieren

Department of General Surgery, Clinic Gummersbach, Academic Hospital University of Cologne, Gummersbach, Germany 


\section{References}

1 Winslow ER, Fleshmann JW, Birnbaum EH, Brunt LM. Wound complications of laparoscopic vs open colectomy. Surg Endosc 2002; 16: 1420 - 1425

2 Singh R, Omicciolo A, Hegge S, McKinley C. Does the extraction-site location in laparoscopic colorectal surgery have an impact on incisional hernia rates? Surg Endosc 2008; 22: $2596-2600$

3 Franklin ME, Kelley H, Kelley M et al. Transvaginal extraction of the specimen after total laparoscopic right hemicolectomy with intracorporal anastomosis. Surg Laparosc Endosc Tech 2008; 18: 294-298

4 Ooi BS, Quah HM, Fu CWP, Eu KW. Laparoscopic high anterior resection with natural orifice specimen extraction (NOSE) for early rectal cancer. Tech Coloproctol 2009; 134: $61-64$

5 Cheung HYS, Leung ALH, Chung CC, Li MKW. Endo-laparoscopic colectomy without mini-laparotomy for left-sided colonic tumors. World J Surg 2009; 33: 1287 - 1291
Bibliography

DOI $10.1055 / \mathrm{s}-0030-1255978$

Endoscopy 2010; 42: E346-E347

(c) Georg Thieme Verlag KG Stuttgart · New York . ISSN 0013-726X

\section{Corresponding author}

\section{S. Saad}

Department of General Surgery

Clinic Gummersbach

Wilhelm-Breckow-Allee 20

51643 Gummersbach

Germany

Fax: +49-2261-17-1615

stefansaad@aol.com 